ABSTRACT: The epidermis notion of the images aims to emphasize the esthetical effect of surface, which both the productions of Pop Art and of "decollagistics" of the New Realism have brought to the modern art sphere. The counterpoint represented by the french romance written by L.M.G. Le Clézio, The war (1970) reveals to which extend the devrirsuperficial of the word representation was established in that time as being the only way to reach all reality sense categories.

KEY WORDS: Pop art, new realism, epidermis, material ecstasy, surface phenomenology.

RESUMO: A noção de epiderme das imagens quer salientar o efeito estético de superficie que as produçôes tanto da Pop Art quanto dos "decollagistas" no Novo Realismo trouxeram ao âmbito da arte moderna. $O$ contraponto representado pelo romance francês de J. M. G. Le Clézio, La guerre, de 1970, revela em qual medida o devrir-superficial da representação do mundo impôs-se nessa época como o único viés para remeter às camadas do sentido da realidade.

PALAVRAS-CHAVE: Pop art, novo realismo, epiderme, êxtase material, fenomenologia da superficie.

\section{STÉPHANE HUCHET}

\section{A epiderme das imagens \\ ou a arte da guerra pop}

Tradução

Ivânia Machado

Revisão da Tradução

Elsa Maria Nitsche Ortiz

Porto Arte, Porto Alegre, v.8, n.14, p.7-24, mal. 1997 
ACES. O título de um filme de John Cassavetes de 1968. A câmera sempre muito próxima dos rostos. Eles são como a matéria do filme. Nos homens, granulosos e marcados. Toda a psicologia parece ter remontado a eles. As vozes são freqüentemente gritantes, indiscretas, irritantes. O nervosismo investe o filme. Em seu romance de 1970, J. M. G. LE CLÉZIO (1992) teria podido compará-lo a um estado de "A guerra". A guerra, segundo Le Clézio, é a expressão aguda, violenta e totalizante, o conjunto das manifestações que dão à civilização técnica sua cara, seu esqueleto, sua anatomia, sua fisionomia mais revelada. Até dobrar e penetrar nossos corpos. Nossos corpos tornam-se, às suas custas, um dos locais de interferência da mecânica orgânica e de sua arquitetônica universal reinando sobre o mundo. Disso, a dança rock em Faces oferece, em menor escala, um quadro perfeito de energia generalizada. Le Clézio faz de um momento literário, um movimento de fenomenologia. A guerra é um livro que dá uma expressão à "physis" contemporânea e ao que Heidegger mostrou sob o conceito de Fim da metafísica: o reino absoluto da técnica. A extraordinária fenomenologia material de Le Clézio é também uma nomenclatura moderna de "nossos" objetos e de "nossas" coisas, uma cosmolo- gia urbana (cidades, auto-estradas, aeródromos, grandes magazines, boates onde poder-se-ia ouvir Deep Purple in Rock $^{l}$ violento e elétrico, subterrâneos, estacionamentos, estruturas e infra-estruturas, etc.). Esse romance, que constitui uma visão psíquica e fisiológica do Ser de nosso Mundo Industrial, sua Poética, articula a substância ao movimento e dá a um ser humano o privilégio, através de seu olhar, de ligar ao significado o movimento tectônico do mundo. (É, assim, secretamente aristotélico.)

É a visão primeira. O mundo toma forma com a atividade perceptiva e cognitiva de Bea B. Essa contraheroína choca-se com os enigmas e com as evidências da superfície do mundo que a cerca e a atravessa com uma intensidade que teria feito um construtivista dos anos 20 delirar com seu poder de pôr o Homem no cruzamento das energias da realidade mecânica e de submetê-lo a essas energias. (Os construtivistas pensavam: regenerá-lo.)

Superficie, sempre superficie. É bem no começo do século que a pintura faz do trabalho de superfície um destino. A imagem de arte, mônada, comunicando com suas vizinhas no Universo, mesmo presa em uma metafísica da regeneração profunda, conheceu um destino de superficie. Tal é o ponto de partida possível de uma história da arte que se interessaria por sua 
pele, por sua epiderme. Mas uma história filosófica que, falando de superficie e de pele, ali veria um "acontecimento" no sentido que lhe daria Deleuze em 1969 em Lógica do sentido: um acontecimento que é uma maneira de estar-no-mundo, de preparar-se para ele e de trabalhar seu sentido e expressão:

"...chegar a essa vontade que nos produz o acontecimento; tornar-se a quase-causa do que se produz em nós, o Operador; produzir as superficies e os forros onde o acontecimento se reflete, se reconhece incorporal e manifesta em nós o esplendor neutro que ele possui em si como impessoal e pré-individual, além do geral e do particular, do coletivo e do privado-cidadão do mundo" (DELEUZE, 1973, p.203).

O acontecimento do destino de superficie da arte e da pintura no começo do século, é uma intensidade nova do ser no mundo que passa, entretanto, por uma modalidade material. Em Cézanne, Vuillard, Bonnard, a liberdade, permitida à tela de aparecer como um dos elementos materiais da pintura, precede uma outra forma de afirmação do material artístico nos papéis-colados de Braque e Picasso, que integram à tela matérias alógenas; eles parecem dar-lhe uma sósia metafórica dela mesma. É necessário sair materialmente de sua condição de suporte sempre negado, primeiro enquanto matéria, para reencontrar-se. Na forma de papel colado, de jornal, de tíquete, de tecido, de resíduo, a matéria-prima do novo começa a parecer por si mesma. É uma conquista fundamental. $\mathrm{O}$ nascimento do monocromo com Malevitch e Rodtchenko precipita a queda da imagem na matéria. A não-figuração absoluta a reduz a suas puras condições materiais. Essa sensibilidade monocroma renasce, em condições certamente diferentes, nos Estados Unidos, após a Segunda Guerra Mundial, numa proporção notável. A Pop Art americana irá, nos anos sessenta, gerar, à sua maneira, essa epiderme da pintura - que, notemo-la, poderia ser o suporte expressivo de uma pesquisa metafísica nos monocromos, no sentido de que a imagem, aí, se torna um tipo de espaço escorregadio e mesmo vazio. Os olhares metafísicos do Expressionismo Abstrato (de Newman e Rothko, por exemplo) dos anos 50, vêem-se ultrapassados pela afirmação de uma sensibilidade sociológica. A posição crítica face à sociedade de consumo, industrial e publicitária, posição muito debatida, é ambígua. Mas, mesmo superficial em aparência, sua relativa neutralidade crítica tem um estatuto ôntico na história da arte ou no mundo da arte. Mundo da arte, ou seja, sua esfera (relativamente autônoma) e as relações que ele mantém com o mundo (a sociedade) próximo e ambiente. Disso, o romance de Le Clézio vai, no fim dos anos 60 , desenhar as fortes e fantásticas linhas. 
Pelo viés da imagem de arte, postulamos que a pintura faz do mundo uma imagem, faz imagem do mundo, e que o mundo faz seu auto-retrato (crítico?) na imagem que os artistas nos dão dele. No nascimento da Pop Art, os críticos de arte americanos julgaram-na, muitas vezes, como uma estética da sociedade de consumo e de suas solicitações generalizadas: as mitologias do cotidiano como prêt-àporter: artigos comerciais e fetiches da moda, toda uma panóplia que constitui as roupas de uma época, sua publicidade (seu caráter público), a "res publica" no teatro da comunicação dos objetos, a república (da) cosmética, poder-se-ia dizer. Artistas como Andy Warhol, Roy Lichtenstein, Tom Wesselmann, James Rosenquist e Claes Oldenburg, por exemplo, deram uma expressão visual a essa "couraça" objetal do mundo publicitário e comercial. (Deixamos voluntariamente de lado Andy Warhol que é, por si mesmo, um emblema do destino de superfície das imagens, sejam elas sociais ou fantasmagóricas.) Como igual número de elementos das entranhas e dos mecanismos da "guerra" lecleziana mesmo imperceptível, os artistas Pop criaram alegorias da sociedade americana que nos aparecem como as estufas frias da (pequena) burguesia consumista. Suas imagens, seus objetos são uma rapsódia da estética comercial que diz ao muito hostil crítico Harold Rosenberg que, com a Pop Art, "a tribo das galerias de arte e dos museus 'acultura' os produtos dos supermercados, das lojas femininas e dos outdoors, passando-os por um filtro de história da arte" (ROSENBERG, 1992, p.113). Lichtenstein, escreve ainda, "homogeiniza a arte 'vulgar' e as formas da grande arte, a grande arte, os derivados dos meios de comunicação de massa: anula o conteúdo de um e de outro, deles não deixando outra coisa senão o Grafismo" (Ibidem, p. 118). Assim, há em Lichtenstein, com seus decalques de trama Ben Day, um trabalho sobre o estereótipo mecânico da imagem. A sociedade re-presenta-se a si mesma nessas superfícies de exibição artística que, no caso de Wesselmann, são igualmente imagens do kitsch: a imagem como artigo (de estética comercial). Oldenburg, um dos promotores do "happening" com Jim Dine pouco antes de 1960, e pouco depois de John Cage, vê na Pop Art "naturezas mortas digeridas pelos meios de comunicação de massa" (OLDENBURG, 1966, p.22). Rosenquist, antigo muralista publicitário, campeão de afrescos glacês, confessava estar "fascinado, excitado pela maneira como 
as coisas nos são jogadas na cara (...) rádio (...) televisão e as outras formas de comunicação" (ROSENQUIST, 1964, p.63). Henry Geldzahler, conservador no Metropolitan Museum, via na Pop Art o efeito de uma "história de arte instantânea" provocada pela imprensa popular, os primeiros planos no cinema, o tecnicolor, etc., todas "imagens barulhentas que irromperam em nossos lares (...,) num soniunto extremamente poderoso, constrangedor e onipresente" (GELDZAHLER, 1963, p.37). O famoso quadro feito por Lichtenstein do retrato de Madame Cézanne transformado em diagrama participa dessa veia mecânico-formalista que permitiu julgar a Pop Art como um correspondente das estéticas formalistas e minimalistas dos anos 50 e 60 (Rosenberg, Donald Judd). G. R. Swenson pensava que a Pop Art . fosse um momento da revoluçāo permanente da pintura. Mas seus puros efeitos de superficie oferecem um espaço dialético para "pôr" essa roupa estética generalizada face ao olhar cognitivo. Lichtenstein jogava, assim, com a pequena "diferença entre sua obra em H. Q. e suas fontes, os "cartoons", por exemplo, que, dizia ele, "conseguem exprimir em açōes violentas (...) em um estilo mecânico e distante" (LICHTENSTEIN, 1964, p.63). Como escreve Pierre Stercloc a respeito de Rosenquist, o que mostra este artista "a partir de imagens desencarnadas, de embalagens e de anúncios, são as fases, os tempos, de uma abordagem polissensorial do visível, segundo as condições concretas, hoje incontornáveis, do meio urbano" (STERCKX, 1991, p.95). Essa função do olhar é eminente no romance de Le Clézio: "Bea B., ou Beauty Lane (...de) corpo cintilante de Bothrops Atrox, que vai seguramente ao outro extremo do labirinto parir seus fetos de dinamite e de algodão-pólvora (e de quem) é preciso arrancar a nele e deixar , penetrar em seu corpo o ar e a água (...) prisioneiros dos canos e das torneiras" (LE CLÉZIO, 1992, p.228), verdadeira Isis de ficção-científica, símbolo e objeto sexual muito próximo das pin-ups nuas no banho de Wesselmann, usuária de batom, seguindo as pegadas de uma lagarta, de Oldenburg, de 1969; essa Bea B. que aprende o alfabeto - (o bê-ábá) da couraça e das entranhas das cidades - é um sujeito sob o olhar de quem nasce o mundo.

A realidade tem olhos. É totalmente sensível. Seu acontecimento (Deleuze) é o objeto de uma visão quase eidética... O Olhar nos desertou, mas ele volta-se em nossa direção, começando sua punção (pensemos em Lichtenstein) a partir do tecido do real. Cheio de espelhos refletores, superfície sobre a qual Le Clézio escreve: "o pensamento é desdobrado, (...) os mistérios não estão no interior, (...) tudo isso se passa na superfície, conduzindo suas numerosas raízes em direção à atmosfera, e a realidade tem milhares de 
olhos. (...) No fundo do poço o que brilhava, era sempre a superficie" (LE CLÉZIO, 1992, p.231). É ainda pensando na escalada estóica dos incorpóreos evocada por Deleuze que se sentirá o quanto a cosmologia urbana de Le Clézio mostra a terra estalar, mover-se, exorbitar-se, exceder-se, como sob um impulso fantástico mas oculto, à imagem desse esverdeamento, desse crescimento que Deleuze devolve à palavra de Paul Valéry: o mais profundo é a pele. "Descoberta estóica" da pequena Alice, acrescenta (DELEUZE (1973, p.18) "que sabe que os acontecimentos dizem respeito tanto mais aos corpos, os cortam e os machucam ainda mais quando eles percorrem toda a extensão sem profundidade" (ibid).

Pelo título de seu ensaio de 1967, Le Clézio nos oferece a fórmula de uma expressão total do mundo, esse trabalho de ascenção à superfície: Extase material, eis a fórmula ideal. EXsistência da matéria, sob mil formas. "Todos, com nossos cupins, nossos ninhos de lagartas, criamos a pirâmide que avança (...). Nós somos obras. OBRAS. É um êxtase sem nome estar assim no ápice" (LE CLÉZIO, 1971, p.143-144). Pintura lubrificante e Wesselmann, mulher inteira e radiografada evocada por LE CLÉZlO (1992, p.219) todos os "diagramas dilatados": ${ }^{2}$ a técnica faustiana vinga-se do homem: "Não era necessário inventar as fotografias", proclama LE CLÉZIO (1992, p.240). "Agora elas se vingam, é o mundo inteiro que se torna plano, liso, paralisado em sua pose grotesca" (id.). Ele formula aqui uma das características essenciais da fotografia, já evocada por Siegfried Kracauer nos anos 20. "Sobre o corpo das mulheres, as roupas colaram à pele, o nylon e a seda soldaramse às células vivas" (id.). Segue-se uma descrição alucinante, entre outras também alucinantes manifestações do acontecimento e da energia que habitam a menor estrutura do mundo, microcosmos ou macrocosmos dos objetos. Para ironizar, tem-se os objetos de plástico, as máquinas de escrever, o lavabo, os toaletes moles, o hambúrguer, com os quais Oldenburg enche sua loja de objetos gigantes e de esculturas moles (the Store), que denunciam a vulgaridade materialista. Trabalha-Ihes o segredo, a fragmentação, o gigantismo e a obsessão. Mas seus desenhos, diz ele, "ilustram a irracionalidade, a alienação, a violência, a incapacidade de exprimir-se plenamente, todas as forças vitais assassinadas na rua" (KOKKINEN, 1971, p.12). Aqui, a versão é trágica, baudelairiana, a sub-face do cosmos urbano, cujos artigos - imagens da Pop Art são como máscaras. Se a Pop Art é uma arte do ambiente vazio ou da saturação cosmética, é também um véu lubrificado da realidade social. A América da guerra do Vietnã: Rosenquist (F111, 1965) denuncia alegoricamente o complexo militar-industrial americano 
num grande afresco. $O$ alemão Volf Vostell, na sua célebre colagem Miss America (1968), superpõe as imagens de um prisioneiro vietcongue aterrorizado e de uma pin-up. Essas expressões visuais são como a rejeição que Bea B. evoca em seu diário, da imagem do corpo sobre uma superfície dura. Bea B. expulsa seus olhos, sua linguagem, sobre uma parede que se parece com o filme fotográfico. Ou com as colagens de Rauschenberg.

É preciso, com efeito, voltar a Rauschenberg para conhecer um momento forte no destino $\mathrm{d}(\mathrm{a})$ superfície na arte. Uma arte epidérmica. O mais célebre é a cama do artista (BED, 1955). Antes de passar às serigrafias contendo, por exemplo, fotos comprimidas entre duas camadas de tecido, Rauschenberg fez trabalhos sobre o plano reposicionado da obra, "o plano flat bed do quadro" como escreveu Leo Steinberg em 1968. Afirmação da materialidade dos planos, o plano do quadro em Rauschenberg é o equivalente de uma "tela de projeção cinematográfica, com afinidades particulares para tudo o que é achatado e que já foi usado: palimpsesto, placa apagada, prova do impressor, folha de rascunho, diagrama, mapa, vista aérea". 3 Steinberg compara essas colagens e esses combinepaintings (a partir de 1955) a um cérebro que teria registrado tudo do mundo exterior, mesmo de "dados brutos que vêm se inscrever sobre um quadro so- brecarregado" (ibid). Os efeitos de matéria são numerosos, por exemplo, o achatamento de uma camisa com uma camada de pintura. Já em 1951, Rauschenberg dizia de seus White paintings, monocromos brancos, que "seu criador é hoje" (DURAND, 1989, p.21). Sua função de espelho refletor os faz semelhantes aos espelhos da realidade evocados por Le Clézio. Mas mais ainda, essa função de imagem é patente em Red paintings (53-54) e combinepaintings. Jogos de superfície, efeitos de trama e de textura onde a tela parece transpirar e absorver inseparavelmente fragmentos de jornais, papéis velhos, chapas, camadas de pintura, etc. num processo de acumulação, de esmagamento ou de impressão. São blocos de energia, uma sintaxe material e enérgica, como a águia empalhada, o bastão, a corda e o travesseiro de Canyon (1959). A visão de Le Clézio da cidade e, além, da tectônica de nosso mundo industrial e mecânico é parente das alegorias materiais de Rauschenberg. Elas devem sugerir a simultaneidade das coisas que nos atravessam e que nos cercam, a "mecânica de guerra", a logística de nossa sociedade hipertecnicizada e hiper-racionalista, teria dito Adorno.

Nesses mesmos anos, artistas europeus vão trabalhar as paredes das cidades. São os "descolagistas", Hains e Villeglé desde 1949, e Rotella em 1953, que trabalha com cartazes políti- 


\section{$14 \square$ Estéphane Huchet}

cos, comerciais, depois da Cinecittà. Cartazistas, eles percorrem as ruas, arrancam as publicidades, recuperam-nas, se apropriam delas, levam-nas a seus ateliers, aplicam-lhe marufle, retrabaIham-nas, colam-nas sobre tela (ou sobre chapa, Hains), redespedaçam-nas, expoem-nas como ready-made, "archimade" dirá o poeta ultra-letrista e inventor do gritoritmo, François Dufrêne. No fim dos anos 50, em 1959, Hains chega a tomar paliçadas feitas de pranchas de madeira e propõenas ao público com seus cartazes na Primeira Bienal de Paris. Descle o fim dos anos 40 , ele trabalha com

Esses farrapos anônimos e epidermicos das cidades constituem uma espécie de fisionomia cultural. çaria medieval de Bayeux! A natureza elementar do papel dos cartazes, das cartas e dos slogans condensa o espírito urbano em um pequeno monumento emblemático. Se se retomassem certas palavras do Athenaeum dos Românticos de lena, poder-se-ia falar, a respeito de Hains, de Villeglé, de Rotella e de Dufrêne de "genialidade fragmentar", de Witz, ou de sociabilidade absoluta" (LACOVE-LABARTHE, 1978, p.114, 126). É seu olhar que é totalmente social no momento em que integra à percepção intuitiva e cognitiva de um espaço e de um suporte público e urbano uma dimensão lentes e objetivas deformadoras de máquinas fotográficas, rompendo, reduzindo e explodindo imagens de objetos, cartas, tipografias: são as fotografias ditas "hipnagógicas". ("Hipnagogoscópio" para o filme de animação de colagens abstratas chamado Penélope: está-se já na temática da trama e da textura do visual.) É um tipo de arqueologia, sob um olhar foto/cinematográfico, efeitos de trama dos cartazes lacerados. A ênfase está nos efeitos de borrão e de sobreposições da imagem enquanto pura superfície. Hains e Villeglé, associados, fazem a partir de 1949 uma colagem de cartazes lacerados e aplicam-lhe marulle sobre tela, Ach Alma Manetro, eco moderno da tape- universal (coletiva). Villeglé declarou que havia procurado "reconstituir a obra estética de um inconsciente coletivo, personalizar esse coletivo anônimo" (GROUT, 1991, p.108).

Os germes de "La Ville NouvelleRéaliste" e "lecleziana" já se encontram em cada uma de suas mônadas e criam uma vizinhança generalizada de homens e coisas. "Com essas ruas fez-seme como os outros homens e os homens como as outras coisas" (LE CLÉZIO, 1971, p.241). Exxtase material da Rua, rosto mural das cidades, arquétipo e corpo homogêneo (ibidem, p.234): muitas páginas de Le Clézio sobre esses "pequenos deuses" (ibidem, p.56): as superfícies das paredes apresentam as 
assinaturas das civilizações (...). O velho metal corroído, o concreto amarelado de urina, o jornal despedaçado que encharca na lama da sarjeta, as marcas dos saltos-agulha das mulheres, (...) tudo isso formou um bloco compacto, indissolúvel, tudo isso mostrou seu desenho preciso e momentâneo, tudo isso foi a alma" (ibidem, p.242). A invenção de Hains, Villeglé, Rotella e Dufrêne, é a interrupção sobre certos panos degradês de nosso tecido urbano para assumi-los numa assunção lúdica: dar vida à natureza morta do real. Suas descolagens, seus recortes retratam com humor a idéia moderna de uma expressão do humano na linguagem e na forma das coisas, uma idéia de Adorno a propósito do Surrealismo: homens, coisas presos num mesmo algarismo. Pensase na extraordinária sentença de Deleuze sobre o Acontecimento: sua explosão é o sentido. No "puro expresso que nos faz sinal e nos espera", acontece "uma espécie de salto no mesmo lugar de todo o corpo que troca sua vontade orgânica por uma vontade espiritual que quer (...) alguma coisa no que acontece, algo a vir conforme - que acontece, seguindo as leis de uma obscura conformidade humorística: o Acontecimento" (DELEUZE, 1973, p.204). ...Grande idéia que não impede, muito pelo contrário, de inscreverse numa atitude de denúncia política, a propósito da França dilacerada (HAINS, 1961) pela guerra da Argélia, por exemplo. O poeta letrista François Dufrêne escolheu o reverso dos cartazes para exaltar, diz ele, "as infra-estruturas, quase geológicas de uma matéria que aí perde (...) sua memória" (GROUT, 1962 , p.107). Essa veia crítica e humorística implica em um trabalho com a manifestação repentina e imediata da monumentalidade inerente ao reencontro instantâneo do insólito dos signos. É um monumento do instante, social. Há uma laceração da percepção nesses cartazes, nessas chapas recobertas de cartazes (HAINS, 1960), nessas paliçadas, onde a trama contínua das explosões formais se organiza no que Jean François Lyotard qualifica de "perturbação que proporciona o reencontro sublime de uma matéria impreparada" em favor de uma "transmissão dos poderes materiais (...) em favor da qualidade táctil do solo, das paredes" (LYOTARD, 1988, p.213, 196).

Esses farrapos anônimos e epidérmicos das cidades constituem uma espécie de fisionomia cultural. Hains, Villeglé e Rotella eram da família dos passeantes benjaminianos. Sua caminhada é "semelhante a um sonho derrubado e disperso pelo dia". Ele "continua a fazer sinal ao acaso e em filigrana durante o trajeto cotidiano (...) como sublevado por uma lenda inédita (em que), assim, a cidade se desdobra, encontra uma espécie de papel sobrelevado, acede a uma densidade e a um resumo escaldantes" (SOLLERS, 1990, p.83). 
O cosmético da Pop Art transborda no romance de Le Clézio. A atmosfera Pop vem aí recobrir as múltiplas evocações das ruas do ensaio de 67, que já oferece verdadeiras listas de objetos que teriam feito a felicidade dos Oldenburg, Rauschenberg, Tinguely, Arman, Spoerri, etc. Objetos decaídos que assombraram ruas, magazines, apartamentos e espíritos. Quase uma enciclopédia em gestação sobre a dimensão material da existência urbana; uma espécie de método sem rigor para assegurar-se, por uma prática laica do "êxtase material", dos fundamentos do nosso estar-aí... Entre excrementos, escarros, cascalhos, tíquetes, Bea B. passa "como uma espécie de carro, com sua capota fechada e todas as suas pinturas que brilham" (LE CLÉZIO, 1992, p.141). Ela está na imagem do mundo: "ela é ao mesmo tempo um motor que vibra e consome as gotas de gasolina e uma espécie de árvore que estende seus ramos carregados de folhas" (ibidem, p.145). Corpo analógo ou participativo.
Como um longínquo eco da visão nauseabunda da árvore-chiclete de Sartre, trinta anos antes, é possível que Le Clézio quisesse reafirmar uma nova sensibilidade existencial. "O êxtase material" como anti-náusea; realismo novo que vê, nas ruas e cidades, às vezes teatros urbanos da deriva ou da vagabundagem ("Nouvelle Vague"), o ponto nevrálgico e cinematográfico da versão contemporânea do estar-lá. O "Lá" ao mesmo tempo libera o ser e o remete a si mesmo. Êxtase. Nossa existência (Pop e Ontológica) passa constitutivamente pela epiderme, que é Imagem e Escritura do mundo. William Burroughs estimava que "a Escritura é uma mensagem que vem sobre toda a pele" (SCARÉTTA, 1982). A Lógica (deleuziana) do sentido passa por essa convicção que permite reler, por exemplo, a arte dos anos 60, como esse Acontecimento de pele que erigiria um retrato do mundo instalado e impresso sobre a camada estreita e a fina materialidade das imagens. 


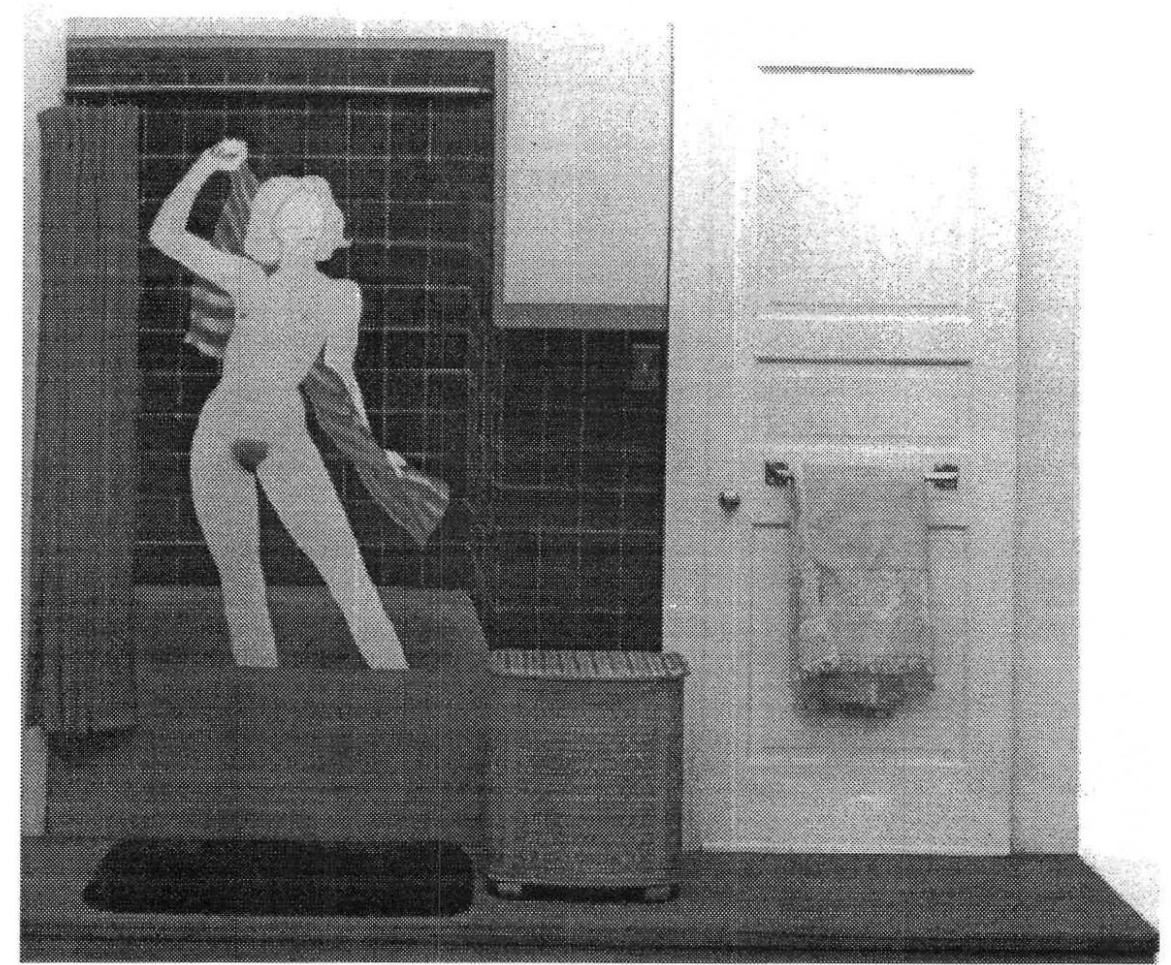

TOM WESSELMANN. Bathtub Collage, 1963, huile sur toile, tissu synthétique, bois, serviette et painer à linge, $213 \times 270 \times 45 \mathrm{~cm}$. Museum Ludwig, Cologne.

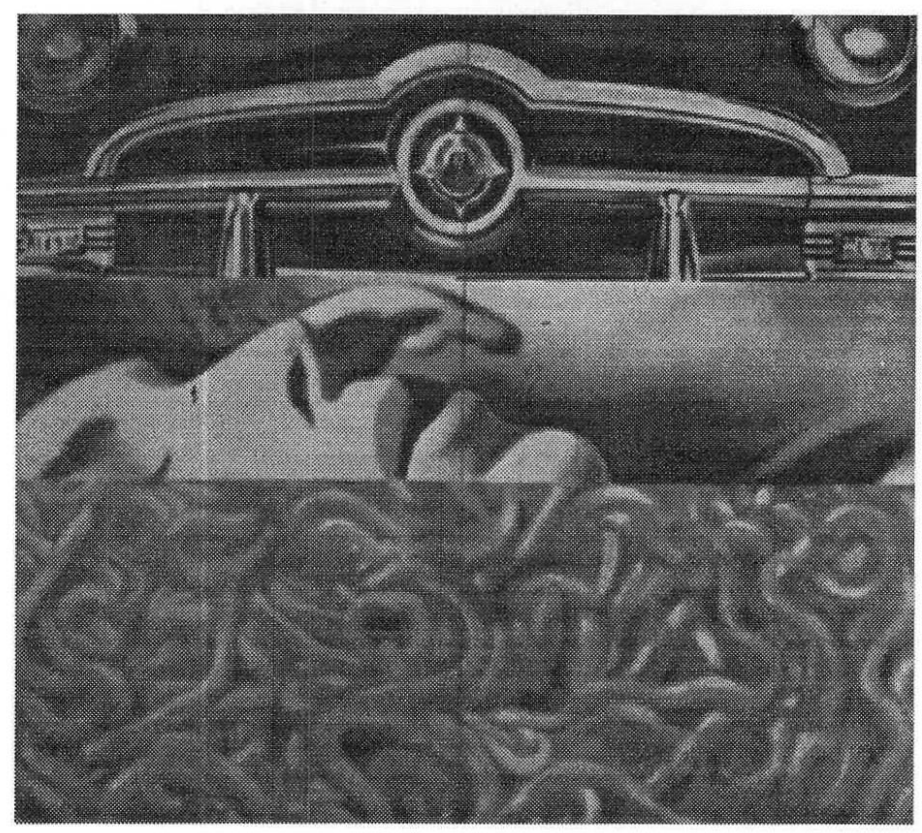

JAMES ROSENQUIST. I love you with my Ford, 1961, huile sur toile, 210,5×237,5cm. Moderna Museum, Stockholm. 


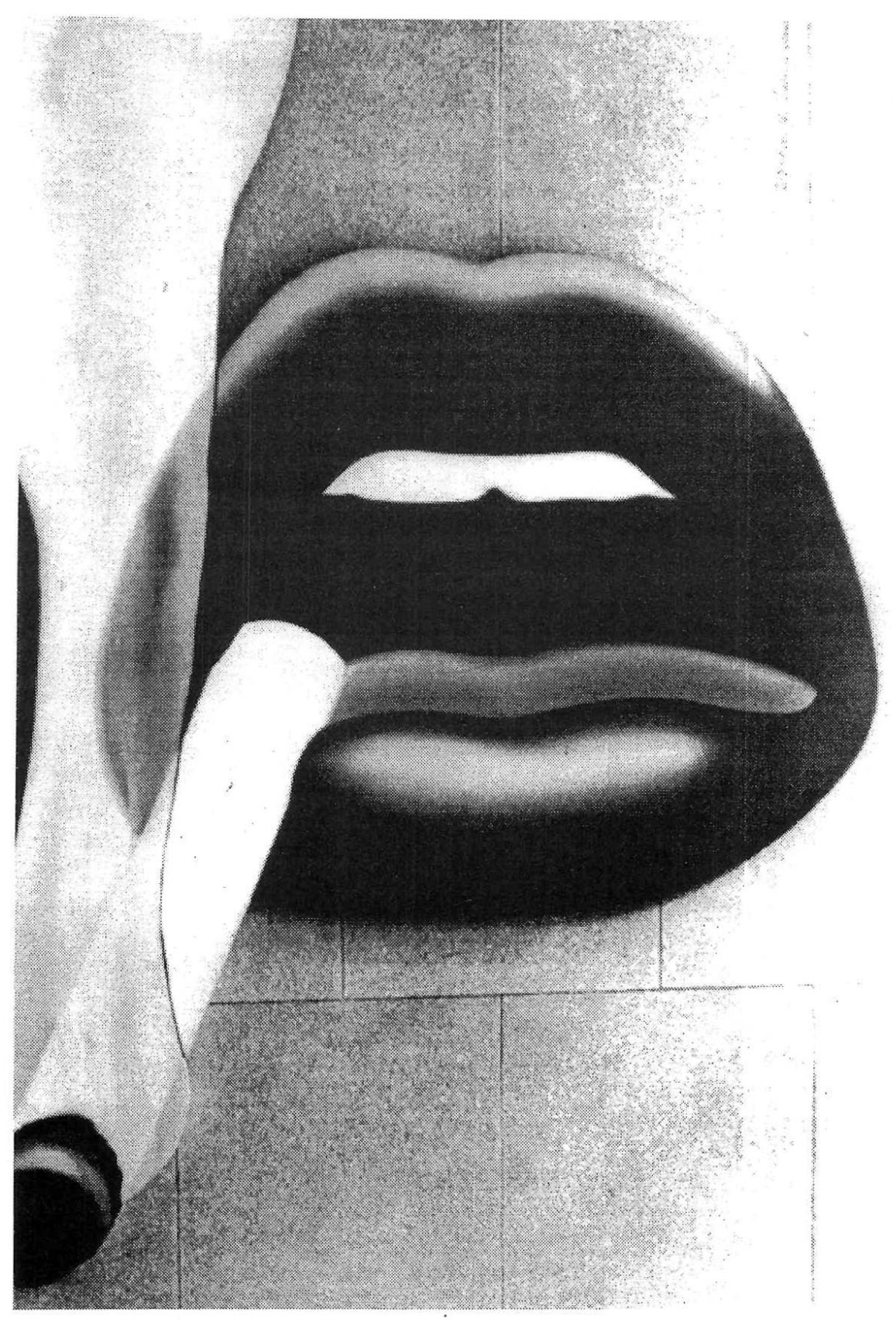

TOM WESSELMANN. Snapshots from the city, 1960. (Instantanés de la Ville), Happening (dans la rue). 


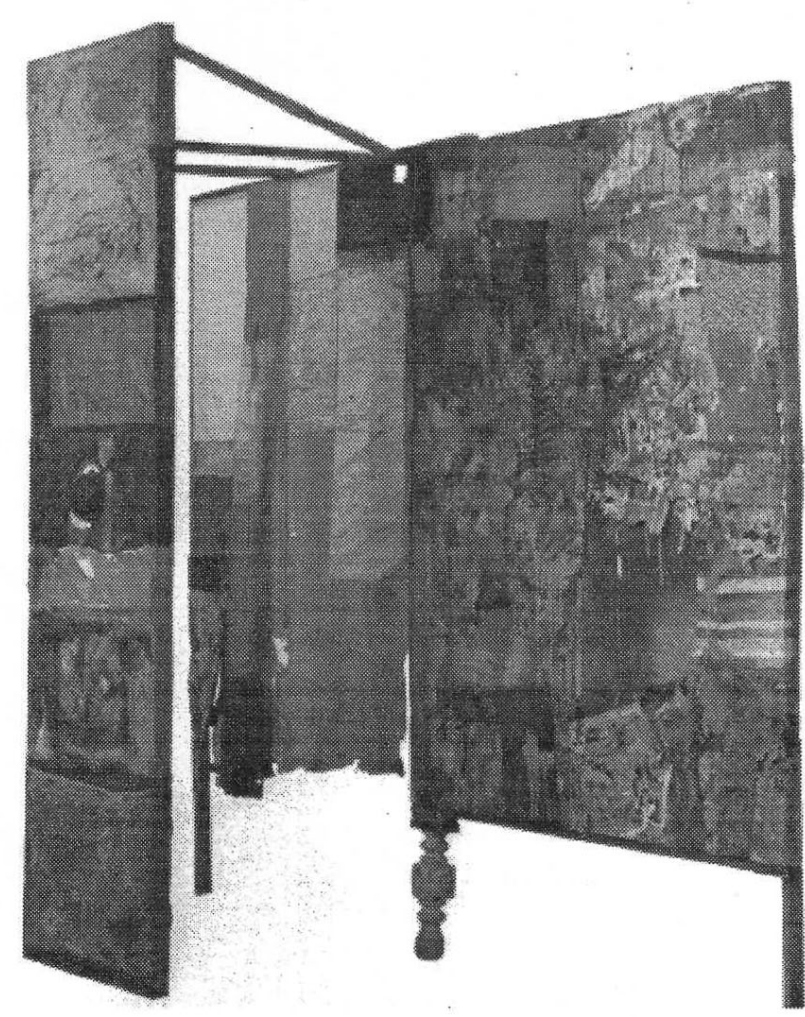

ROBERT RAUSCHENBERG. Minutiae, 1954, huile et collage avec objets, $214,5 \times 2005,5 \times 77,5 \mathrm{~cm}$. Collection de l'artiste.

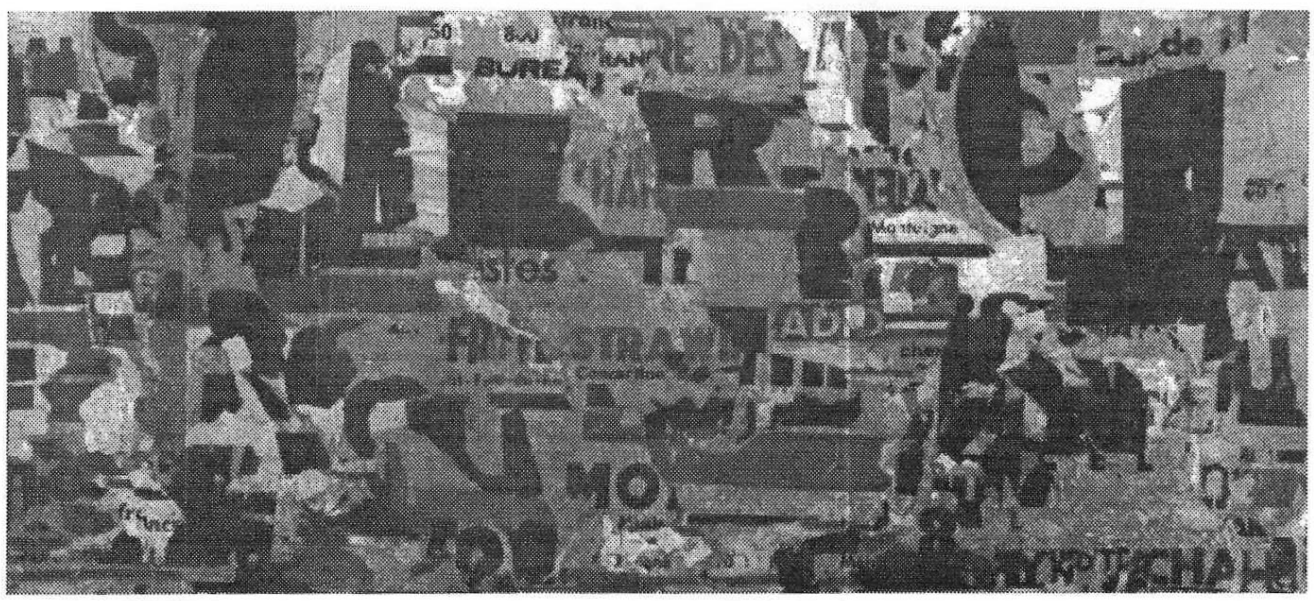

VILLEGLÉ et RAYMOND HAINS. Ach Alma Manetro, 1949. Collage d'affiches lacérées sur papier marouflé sur toile, $58 \times 256 \mathrm{~cm}$. Musée National d'Art Moderne - Centre Georges Pompidou, Paris (Moitié droite de l'oeuvre). 
20 Estéphane Huchet

RAUSCHENBERG. Persimmon, 1959.

Huile, papier, métal, mouchoir, bande transparente, bouton et bois sur toile avec échelle en bois, $229 \times 151 \times 10 \mathrm{~cm}$. Collection particulière.
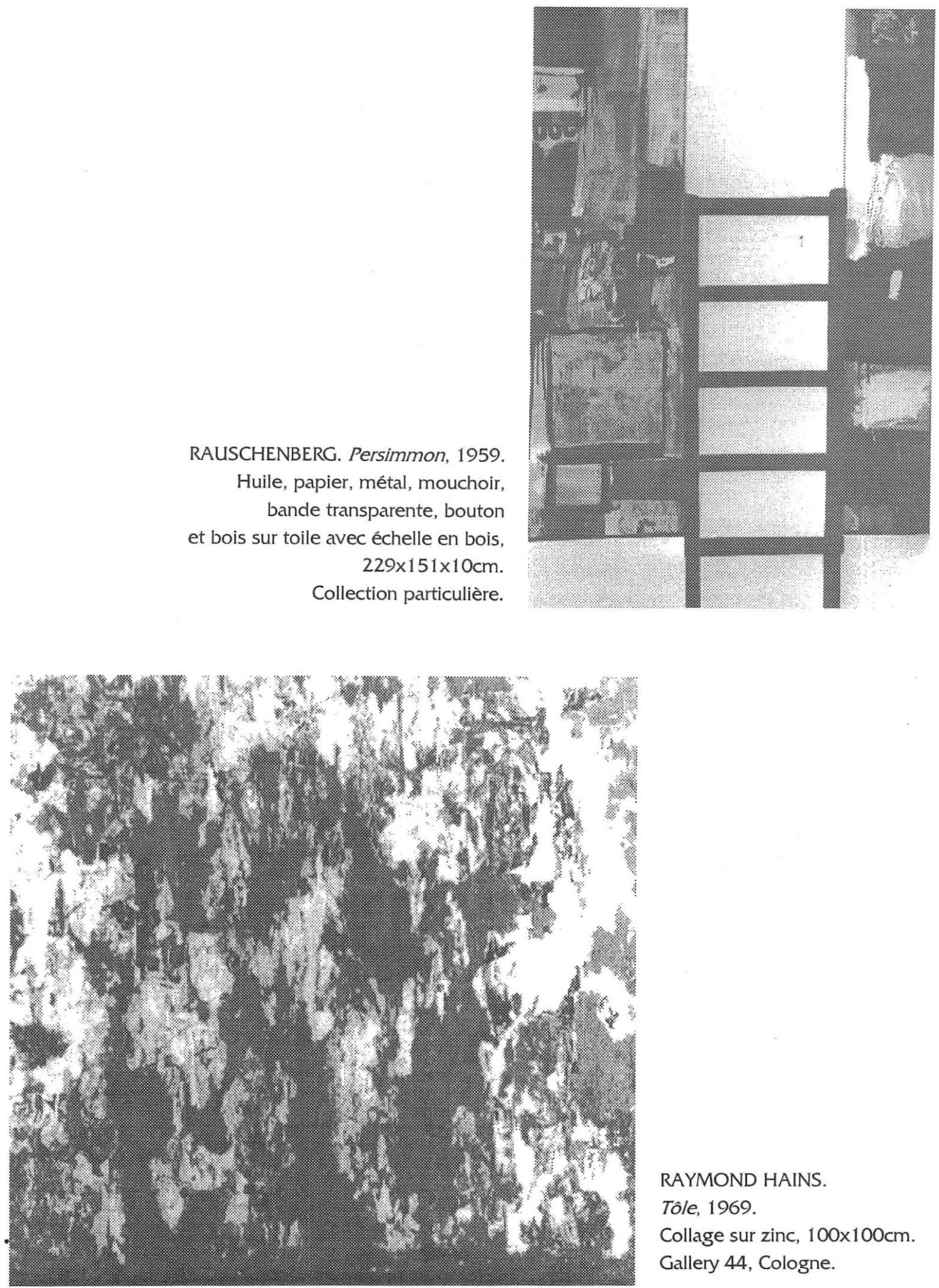

RAYMOND HAINS.

Tôle, 1969.

Collage sur zinc, $100 \times 100 \mathrm{~cm}$. Gallery 44, Cologne. 
A epiderme das imagens ou a arte da guerra pop

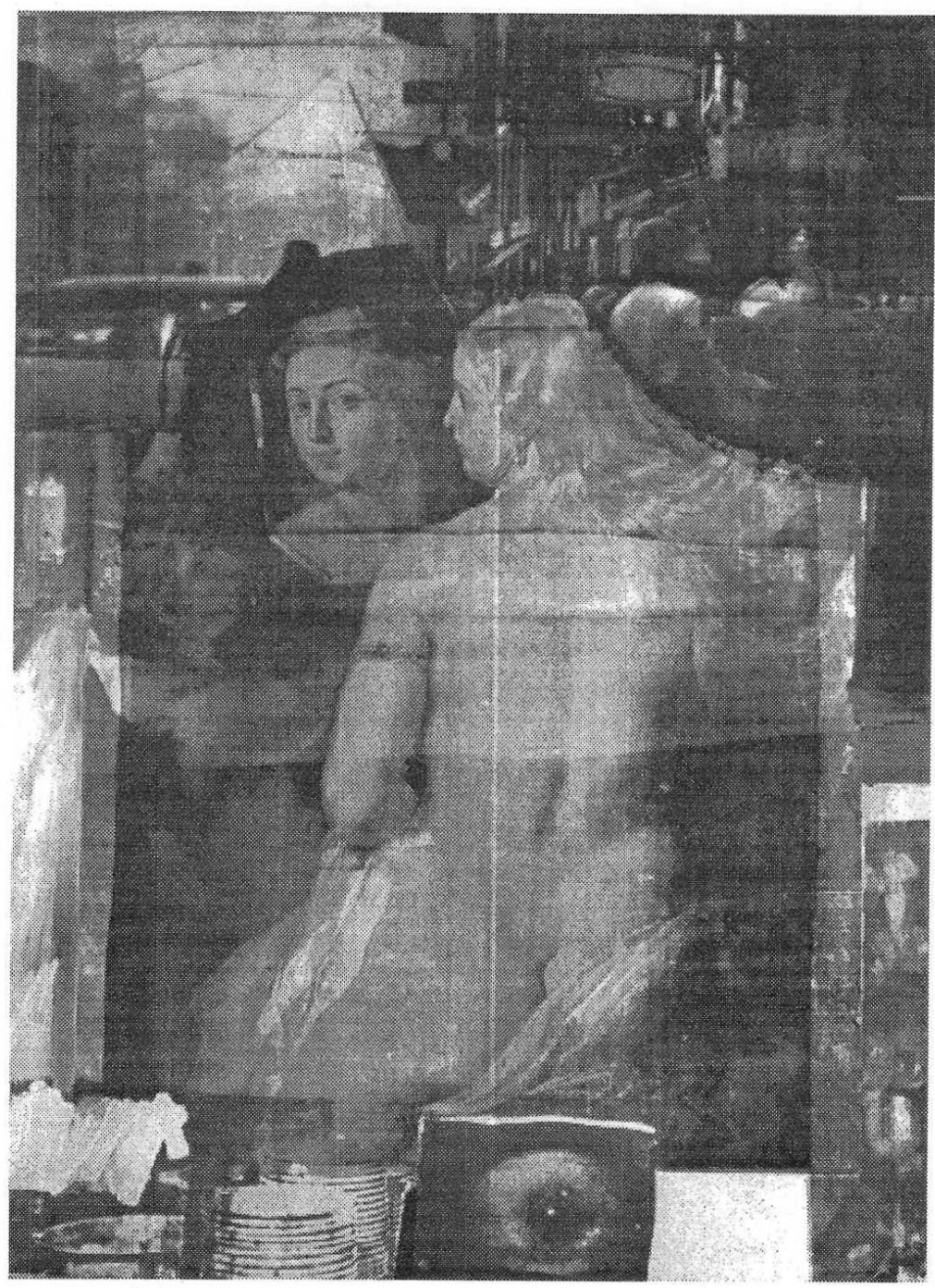

RAUSCHENBERG. Persimmon, 1964. Huile et sérigraphie sur toile, $128 \times 127 \mathrm{~cm}$. Collection Jean-Christophe Castelli. 
$22 \square$ Estéphane Huchet



MIMMO ROTELLA. Flip, 1963.

Porto Arte, Porto Alegre, v.8, n.14, p.7-24, mai. 1997 


\section{NOTAS}

${ }^{1}$ Um dos títulos (1970) do célebre grupo de Pop Music Deep Purple.

2 "Ela fazia mímica ainda. Continuava a representar inocentemente a comédia da espécie. (...) Mostrava seu corpo e sua face impenetrável e não sabia que essa couraça tinha um defeito. Não sabia que se lhe tinha adivinhado, que tinha sido iluminada interiormente, que apesar de suas caretas, de seus esforços, ela estava nua, indescritivelmente nua, translúcida, desmistificada. Não era mais uma mentira. Era uma mulher inteira, com suas sensações e suas idéias, com seus nervos, suas glândulas, sua pele, seu esqueleto, visível como numa fotografia". Ibidem, p.96. Ter-se-ia aqui ao mesmo tempo uma exposição da pin-up, artefato como código neutralizado e, escreve Guy Scarpetta, "uma maneira de exasperar o que, no código em questão, revela sua obscenidade latente, sua embriaguez, sua vertigem, sua dimensão obscura." In L'impureté. Grasset. Paris. 1985. p.85. J. M. G. Le Clézio. La Guerre, p.219.

${ }^{3}$ Steinberg tinha, aliás, uma idéia muito lecleziana quando comparava a tendência formalista da crítica de arte americana com a tendência do design industrial dos automóveis para integrar cada vez mais seus elementos à fuselagem, até fazer disso uma pura forma sintética e compacta/Leo Steinberg. "Other Criteria."In Claude Gintz (anthologie critique). Regards sur I'art américain des années soixante. Territoires. Paris, 1979. p.48

\section{REFERÊNCIAS BIBLIOGRÁFICAS}

DELEUZE, Gilles. Logique du sens. Paris : UGE / Minuit, 1973.

DURAND, Régis. Arte Press, déc. 1989.

GELDZAHLER, Henry. A symposium on Pop Art. Ars Magazine, auril 1963.

GROUT, Catherine. Liquidation du stock. 1962.

Les ravisseurs de la beauté moderne. Artstudio, n.23, hiver 1991.

KOKKINEN, Eila. Claes Oldenburg : drawing and prints. Arts, nov. 1971.

LACOUE-LABARTHE, Philippe \& NANCY, Jean-Luc. L'absolu littéraire. Théorie de la littérature du romantisme allemand. Paris : Seuil, 1978.

LE CLÉZIO, J. M. G. L'extase matérielle. Paris : Gallimard, 1971.

LICHTENSTEIN, Roy. Wat is Pop Art? Entrevistado por G. R. Swenson. 1 èpartie. Art News, fév. 1964. 
LYOTARD, Jean-Francois. L'inhumain. Causeries sur le temps. Paris : Galilée, 1988.

OLDENBURG, Claes. Artforum, fév. 1966.

ROSENBERG, Harold. La definition de l'art. Nimes : Jacqueline Chambon, 1992.

ROSENQUIST, James. Wat is Pop Art? Entrevistado por G. R. Swenson. 2 éparte. Art News, fév. 1964.

SCARPETTA, Guy. L'audio-visuel. Art Press, jui-août 1982.

SOLLERS, Philippe. Drame. Paris : Gallimard, 1990.

STERCKX, Pierre. La peau du collage selon Tom Wesselmann et James Rosenquist. Artstudio, Le Collage, n.23, hiver 1991.

STÉPHANE HUCHET: Doutor da Ecole des Hautes Etudes en Sciences Sociales de Paris. Historiador e teórico da arte, ele foi em 1996 e 1997. Professor Visitante da Escola de Comunicação e Artes da Universidade de São Paulo, dos Institutos de Arte e de Filosofia da Universidade Estadual de Campinas e membro do corpo docente da Escola do Museu de São Paulo. Atualmente Professor na Escola de Arquitetura da Universidade Federal de Minas Gerais, ele desenvolveu nestes últimos anos uma pesquisa sobre as relações entre a arte moderna e a filosofia.

IVÂNIA MACHADO (Tradução do Francês): Mestranda em Letras (em Literatura) na Universidade Federal do Rio Grande do Sul. Bacharelado em Letras - Universidade Federal do Rio Grande do Sul.

ELSA MARIA NITSCHE ORTIZ (Revisão da tradução): Doutora em Lingüística Aplicada. Professora no Curso de Letras da Universidade Federal do Rio Grande do Sul. Graduação (Tradução e Línguas). Pós-Graduação (Teorias do Discurso). 